\title{
Fire Situation and Development of Fire Safety Science and Technology in China
}

\author{
Guo Tie-Nan \\ Fire Department of Ministry of Public Security \\ No. 19, Huawei Xili, Chaoyang District, Beijing, 100021, China
}

\begin{abstract}
The fire direct property damage has gone up significantly with the development of industrialization and urbanization since the 1950's in China. The number of casualties of fire has come down since the 1980's while the mass casualties fire was significant. China governments at all levels, departments of fire protection, and the whole society have made great efforts to promote fire science research and its applications. The fire situation becomes relative stable in recent years.

At present, the strength on fire research in China mainly includes the four fire research institutes of the Ministry of Public Security, the state key laboratory of fire science, fire enterprises and other fire research institutes. The researches have been carried out on fire detecting \& alarming and fire suppression, fire resistance performance of constructions and fire prevention technology, fire modeling technology and performance-based fire safety design, fire protection on urban layout and fire fighting \& rescue, technology of fire protection standardization, fire dynamics and fundamentals of fire protection since 1990. Emphasis has been put on the technology of fire prevention and fire-fighting rescue for high-rise building, underground building and large space building, and technology of prevention and control of urban fire and severe chemical disaster.

In the future 5 years, the fire research work will be developed on theory of fire dynamic and fire risk, evaluation on urban area fire risk and capability of fire protection, techniques of new type fire facilities and engineering application, modernization of fire equipment, techniques of assessment and design on fire resistant of construction configuration, human behavior in fire, establishment and improvement of fire database, economics of fire protection and performance-based fire safety engineering.
\end{abstract}

KEYWORDS: China, fire situation, fire research strength, progress of fire research

\section{ANALYSIS OF FIRE SITUATION IN CHINA}

\section{Overview of Fire Situation}

At the early time of 1950 's, the total fire occurrence and direct property damage were comparatively low, because China was still at the initial stage of industrialization, the urbanization level was only $10.6 \%$, and economic level was quite low. In the 1950's, the annual average direct property damage from fire was about 60 million RMB. With the development of industrialization and urbanization, fire occurrence increased accordingly: the annual average was 140 million RMB in the 1960's; it was 240 million RMB in 1970 's; it was 320 million RMB in 1980's. Along with the increase of the social wealth and the factors resulting in fire, direct property damage sharply rose since the 1990's: the annual average was about 1.06 billion RMB in the 1990's; in the first five years of 21st century, the annual average climbed to 1.55 billion RMB [1,2], see Fig. 1. 
The peak of fire casualties came in the 1960's and 1970's. The annual average death toll was 4,500 and 4,366 persons respectively (see Fig. 2) and 10,843 persons in 1960. After the reform and opening up in 1978, governments at all levels, departments of fire protection, and the whole society have made great efforts to boost the fire science research and its applications. The number fire casualties went down significantly.

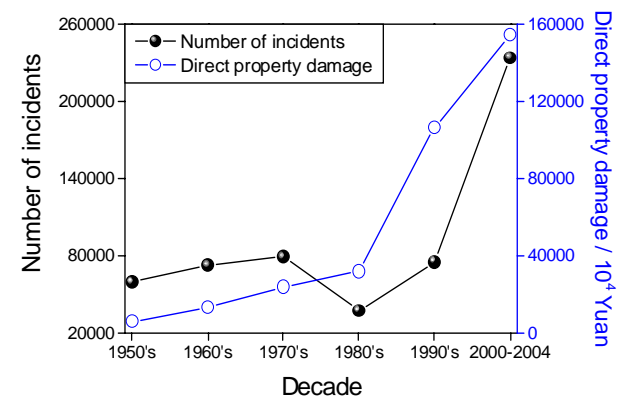

Fig. 1. The number of fire incidents and direct property damage since 1950 in China.

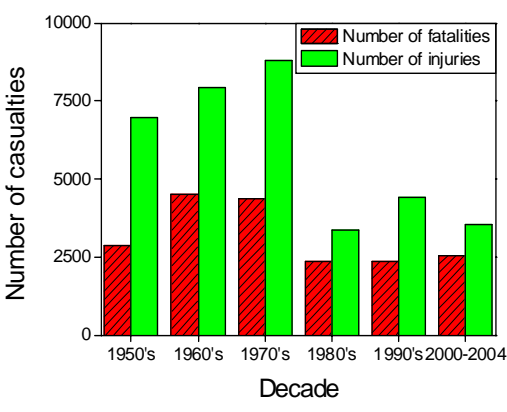

Fig. 2. Number of casualties from fire since 1950 in China.

\section{Features of Fire Situation Since 1990}

\section{Upward Tendency of Fire Direct Property Damage}

In the past 13 years, the gross domestic product (GDP), fixed asserts investments and the income per capita of urban residents increased by 5.3 times, 11.5 times, and 4.5 times, respectively; the increase of urban area $116 \%$, urban population 45 million, total amount of energy consumption 0.93 billion ton, length of the road 0.83 million $\mathrm{km}$, and amount of private cars 15.6 times [3-4]. Accordingly, the number of fire incidents and direct property damage from fire increased by 4.6 times and 2.2 times, respectively. See Fig. 3 .

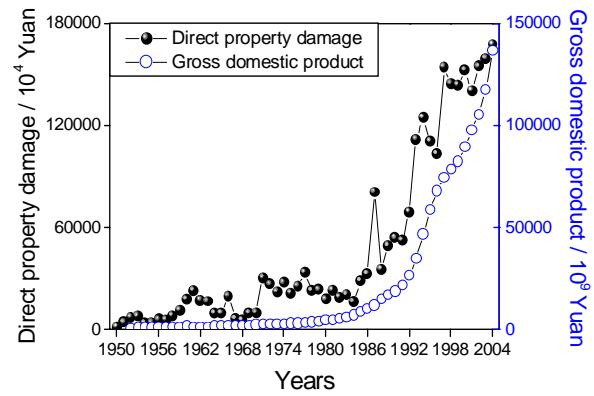

Fig. 3. Upward tendency of direct property damage and GDP.

Comparing with developed countries, the current industrialization and urbanization level, and fire occurrence and direct property damage in China are at a lower level. With the development of economic society in China, the significant change of production mode and living style has been made. More and more sites for people in mass and locations for combustible and explosible material have come forth and the super-scale and complicated building have arisen. The uses of new materials, new techniques and new energy have 
increased. There is a potential rising possibility for fire occurrence [1,5-7]. The experience of developed countries illustrates that a country is in a period of rapid change of social structure and outstanding conflicts when GDP per capita is between 1,000 and 3,000 US\$. In 2003, GDP per capita in China has exceeded 1,000 US\$. Therefore, it will be a significant task for Chinese fire scientists and technologists to study and analysis the rule of fire occurrence with the development of economic society.

\section{Noticeable Problem of Mass Casualties Fire}

Figures 4 and 5 are the serious fire situation since 1990. It gives degressive tendency of the number of incidents and direct property damage of serious fire and the noticeable problem of mass casualties fire. In 1993 and 1994, 124 and 151 serious fires occurred respectively, and the number of fire casualties was 433 and 855 respectively. A fire caused 309 fatalities occurred in 2000.

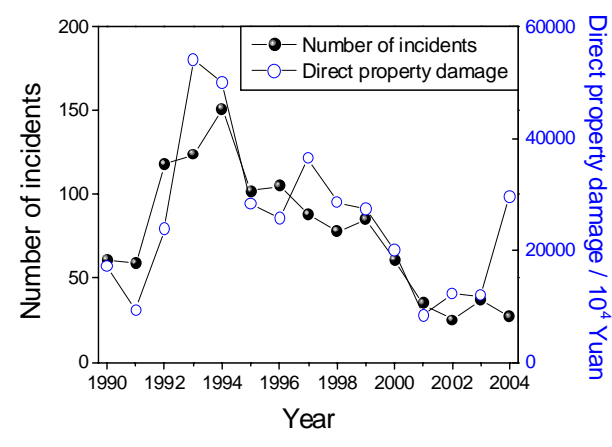

Fig. 4. The number of incidents and direct property damage from serious fire since 1990 in China.

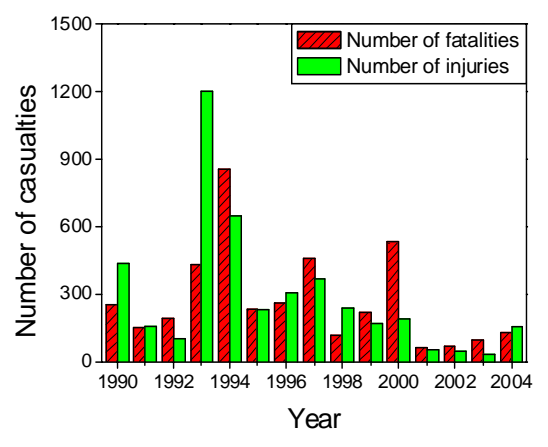

Fig. 5. Number of casualties from fire since 1990 in China.

According to the statistics of 1999-2001, the annual average fatalities rate was 0.21 per 0.1 million people, which was obviously lower than that of developed countries [8]. However, the absolute number of fire casualties was high with annual average fatalities of 2700 due to the large population in China. The mass casualties caused by fire become a serious problem. Since the 1990's, there were 26 cases of catastrophic conflagrations with over 30 people killed in each fire occurrence, and total 2,078 people were killed. The fire happened in Yiyuan Dancery in Fuxin city, Liaoning province caused 233 fatalities on Nov 27, 1994; On 8th Dec 1994, there was a fire occurred in Friendship Palace in Sinkiang Municipality, which caused 325 fatalities. On 25th Dec 2000, a fire occurred at Dongdu Mansion in Luoyang, Henan province, resulting in 309 fatalities. The occurrence of these mass casualties caused severe damage to people both physically and emotionally. At the same time, these conflagrations confront us with an urgent demanding job of finding effective solutions.

\section{PROGRESS IN FIRE SAFETY SCIENCE AND TECHNOLOGY IN CHINA}

\section{Main Strength and Research Facilities on Fire Safety Science and Technology}

Based on the fifty-year's development in the past, especially the rapid progress since 1978, a strength of fire science and technology has been established. The four fire research institutes of the Ministry of Public Security, the State Key Laboratory of Fire Science in University of Science and technology of China, some other fire research institutes and large 
fire protection enterprises makes up of the main body of this force with some other related educational and research organizations as the supplementary.

\section{Four Fire Research Institutes of the Ministry of Public Security}

Tianjin, Shanghai, Shenyang and Sichuan Fire Research Institute of the Ministry of Public Security were built respectively since 1965. The Tianjin Fire Research Institute mainly undertakes the research of fire theory, fire protection engineering, fire codes and management, etc. It owns the fire test and fire extinguishing test laboratory, the construction component fire resistive test laboratory, large-scale oil fire extinguishing test facility, and the National Quality Supervision \& Inspection Center for Fixed Fire Extinguishing System and Fire Resistant Components. The Shanghai Fire Science Research Institute focuses in fire extinguishing theory, fire fighting equipment, fire fighting technique and tactics, fire fighter safeguard in fire scene and so on. It owns the fire equipment performance test laboratory, fire fighter personnel protection equipment performance test laboratory, fire-fighting robot performance test laboratory, and the National Quality Supervision \& Inspection Center for Fire Equipment. Shenyang Fire Research Institute is devoted to the prevention and identification of electric fire, fire detection and fire alarm, fire communication and fire electronic application technology etc. It owns the specialized test apparatus for fire electronic equipment, the simulated control room of the urban fire protection communication and commanding center, the evaluation system of intelligence fire detecting and fire alarming system, the electrical fire study and test facility, and the National Quality Supervision \& Inspection Center for Fire Electronic Product. The Sichuan Fire Research Institute researches in building fire theory, building fire protection, fire-resistant materials etc. It owns the high-rise building fire test tower, underground commercial street fire test laboratory, the building material flammability test apparatus, and the National Quality Supervision \& Inspection Center for Fireproof Building Material.

\section{The State Key Laboratory of Fire Science and Other Fire Research Institute}

In Nov 1995, the State Key Laboratory of Fire Science in the University of Science and Technology of China, the national-class research institute for fire science was established. The spacious fire testing hall, the simulation equipment of forest fire and grassland fire as well as the fire simulation of multi-floor residential buildings are well used in the research of basic fire science, the spread law of forest fire, and grassland fire and the development in high tech intelligent fire technique and new products. In recent years, the State Key Laboratory researches mainly on the fire dynamic evolvement and simulation, principles and basic technologies of fire protection, the theory and methodology of fire safety engineering.

Besides the above-mentioned, the other fire science research institutes are also active in fire science research works, for example, the Building Fire Research Institute established in China Academy of Building Research, the State Key Laboratory of Explosion Science and Technology and the Special Laboratory of Fire Retardant Material founded by Beijing Institute of Technology, the Forestry Protection Research Institute of the State Forestry Administration, and the Far-East Fire Prevention Test Center of the Ministry of Communications and so on. Quite a number of scholars in university have engaged in fire research, such as Tsinghua University, Chinese People Armed Police Force Academy, Zhejiang University, Hong Kong Polytechnic University, Tianjin University, Tongji University, Nankai University, Jilin Industrial University, Chengkung University in 
Taiwan and so on. They play an important role in the system of fire science researches and development.

\section{Achievements on Fire Safety Science and Technology in Recent Years}

The researches in China have been carried out on fire detecting \& alarming and fire suppression, fire resistance performance of constructions and fire prevention technology, fire modeling technology and performance-based fire safety design, fire protection on urban layout and fire fighting \& rescue, technology of fire protection standardization, fire dynamics and fundamentals of fire protection since 1990. Emphasis has been put on the technology of fire prevention and fire-fighting rescue for high-rise building, underground building and large space building, and technology of prevention and control of urban fire and severe chemical disaster.

\section{Technology on Fire Detecting \& Alarming and Fire Suppression}

On the field of fire detecting and alarming, Chinese scholar undertakes the research of high sensitive aspirating smoke detecting and alarming, combination detecting and alarming system by detecting smoke and temperature, double-wave-band infrared blaze detecting and alarming system and linetype combustible gas detecting and alarming system, etc. [9-12]. Specialists of this aspect, on the basis of analyzing applied background information and the changing rule of fire parameter, put forward and achieve three assessing modes, serial testing methods and integrative evaluating mathematical model of fire detection algorithm evaluation [13], and develop the portentous noise monitoring forecasting method of tank fire boiling over [14]. In the field of fire extinguishments, we research the performance of automatic fire extinguishments explosion suppressing dynamics, designing calculating method, fire extinguishments efficiency and mechanism, influence of environment, integration and optimization, and working reliability etc.[15-17]. Making good use of laser holographic and electronic measuring weight technology, our country successfully solves the key technology of three-dimensional space distribution and measuring weight, carries on the research work of effect on fire extinguishments by water mist characteristic, and fog drop field characteristic of fie apparatus, primarily establishes the relationship of different water drop dream field and fire extinguishments efficiency [18-20], develops SD forceful fire extinguishing liquid and High-rise building fire intellectual detection warning system, quick response automatic sprinkler system, circulating startup automatic sprinkler system, remotely controlled fire foam extinguishments system, medium, low-pressure fire pump series, fundamental protecting technical parameters of a fireman in fire fighting field, heat protection testing apparatus, serial fire robots, satellite communications fire commanding system, etc. [21-31].

\section{Research on Fire Resistance Performance of Constructions and Fire Prevention Technology}

Researches in this field mainly cover: theoretical calculations and experimental investigations of fire resistance performance of building components and structural failure process under fire conditions, smoke toxicity analysis for building fires, smoke management techniques, and fire resistance and flame retardant technologies etc [32-43]. In the respect of smoke toxicity testing methods for different materials, China has firstly proposed the simplified assessment method in which rats are intoxicated with the nonflaming smoke produced by the complete combustion of the tested material, and then the 
rats are observed for 3 days. According to the "geometric sequence" based grading method for smoke toxicity levels of materials, a series of new standards such as "Preparation of the Toxic Fire Smoke", "Classification of the Smoke Toxicity of Materials", and "Animal Test Method for the Assessment of the Smoke Toxicity" and so on, have been established [44]. In the aspect of fire resistance and flame retardant technologies, a wide range of products such as fire resistant polystyrene/Mg-Al type LDHs series nanometer compound material, ultra-thin expanded coating SCB for steel structures, fire resistive coatings SWB and SWH for outdoor steel structures, organic fireproof filling materials GF and inorganic fireproof filling materials SF etc. have been developed [45-48]. In the aspect of fire investigation, the fire causes identification technique has been applied based on fire dynamics and trace in fire field [49].

\section{Fire Modeling Technology and Performance-based Fire Safety Design}

Since 1980's, emerged as a new design approach, performance-based fire safety design has been rapidly developed around the world. Since 1990's, China has carried out researches on fire characteristics, testing methods and combustion mechanisms of materials and components [50-60], conducted investigations on fire propagation in ordinary buildings, atrium buildings, large space buildings and underground buildings, smoke movement in these buildings and corresponding computer simulation techniques, evaluation methods of human egress safety etc., and has established fire propagation models, smoke movement models and human egress models for large complex buildings [61-70]. All these achievements have laid an indispensable foundation for further research works on performance-based fire safety design for complex buildings. In the aspect of performance-based fire safety design for large space buildings, Hong Kong Polytechnic University and inland fire research institutes have carried out fruitful cooperation researches [71,72]. In the study of fire smoke, Chinese scholars have proposed and developed the field-zone-network models for building fires, advanced interface treatment techniques for three simulation approaches, and devised the integrated model which has incorporated buoyancy effect, soot production and transport, interaction of turbulence and heat radiation, etc [73]. Two sessions of symposium on performancebased fire safety design for buildings were held respectively in Tianjin, 2003 and in Macao, 2004.

\section{Technology of Fire Protection on Urban Layout and Fire Fighting \& Rescue}

In recent years, China has made vigorous effort in the studies of urban public security planning, emergency planning and preparedness measures. The research results from the project "Urban and District Fire risk Assessment and Fire Protection Planning Technologies" have proposed the main contents of urban fire protection programming, technical requirements and plan constitution processes and methods. The project has enumerated available system types for urban water supply, presented water flow rate needed for putting out one breakout of fires in residential, commercial and mixedoccupancy areas. It has also prescribed the required capacity for urban water supply systems and proposed the optimal configuration and allocation method. Based on the application of the urban fire risk assessment technology and the optimal allocation method of fire-fighting resources, the constitution of the "Technical Guides on the Urban

Fire Protection Plan" has been accomplished [74-76]. In the research of methods and techniques for optimal allocation of fire-fighting and rescue forces, using discrete location-allocation model along with set covering, maximal covering and P-median 
methods, Chinese scholars have established optimal configuration methods for urban fire stations and optimal allocation methods for regional fire-fighting equipment and personnel based on urban and regional fire risk levels. We have also proposed equipment and personnel demands models for regional fire-fighting and rescues by introducing the concept of Worst Case Planning Scenarios, and developed application programs for the optimal allocation of fire-fighting and rescue forces [77,78]. The research of grading methods for urban fires and disasters and response plan constitution techniques for firefighting and rescue forces, has for the first time put forward the classification and grading criteria for urban fires and other disasters, and established the concept of graded response system for fire-fighting and rescue forces [79].

\section{Technology of Fire Protection Standardization}

Since the foundation of the National Technical Committee for Fire Protection Standardization in 1988, China has made notable progress in the aspect of fire protection standardization. Large amount of research achievements have become the scientific criteria for the stipulation of codes and standards. Up to now, 289 standards have been formulated, including "Basic technical standards," "Uniform standards for fire safety engineering," "Uniform standards for fire products," and "Uniform standards for fire prevention management" etc. 28 Codes for fire protection have been constituted and implemented, covering the respects of fire prevention design for construction engineering, and design, installation and commission inspection for fire system and etc.

\section{Research on Fire Dynamics and Fundamentals of Fire Protection}

In order to deepen our understandings of fire phenomenon, and boost the amelioration and development of fire safety design, management and fire-fighting techniques, University of Science \& Technology of China, Fire Research Institutes of Sichuan, Shenyang and Shanghai, Zhejiang University, Hong Kong Polytechnic University and Chinese Academy of Forestry jointly undertook the National Key Project for Basic Research and Development of China "Fire Dynamics and Fundamentals of Fire Protection" in April, 2004. This project focuses on the solution of six crucial problems, i.e., growth and propagation of combustible surface fires and space fires, production and release of fire smoke and toxic substances, fire risk assessment methodology based on fire dynamics coupled with statistical theories, clean and high-efficiency flame retarding technologies with optimal comprehensive performance, multi-signal perception and intelligent recognition for incipient fires, and clean, high-efficiency fire suppression principles under combined physical and chemical effects [80]. Recently, development and establishment of experimental equipment for fire parameter measurement has been completed and prominent achievement has been accomplished [81].

To conclude all above, in the past decades, China has made inspiring achievements in the field of fire safety science and technology, which has laid a solid foundation in many respects such as fundamental researches, experimental facilities, information accumulation, technology exploitation, research teams buildup and international academic cooperation, etc. We are full of belief for the future of fire science and technology in China. However, it should be noticed that, fire safety science and technology in China still could not keep up with the rapid pace of economy, technical innovation capacity in fire science still finds a large margin to improve, and original research findings with independent intellectual property rights are still quite inadequate. Some key techniques are to be broken through, fundamental researches are to be 
strengthened; the conversion of research findings to practical applications still is to be improved.

\section{PROSPECT ON FIRE SAFETY SCIENCE AND TECHNOLOGY IN CHINA}

The first decade in this new century is a important period for the development of China. Presently China has maintained a rapid growth rate in economy and enjoyed a vigorous bloom in social welfares. Since the reform and opening up, the GDP of China has achieved an annual increase of $9.5 \%$. Urbanization maintains a boosting momentum, and scored a level of $42 \%$ in 2004 . However, under such a prosperous trend, many nontraditional fire problems have bulged out. Fires in this modern time have manifested a lot of new features. We will try our best to resolve the contradiction between the everincreasing needs for fire safety guarantee and the relative insufficiency of fire prevention resources, and improve the social capability to prevent and control fires so that everyone living in China could enjoy enough fire-safety guarantee.

Since the dawn of the new century, China adheres to the concept of scientific and sustainable development and has made untiringly efforts to create a human-oriented, harmonious and well-off society. This requires the promotion of the public fire safety level to be more imperative. In the era of information and knowledge economics, science and technology has become the boosting momentum for the development of economic society and public safety. The holiest mission of science and technology lies in safeguard of human rights to survival, development and health. Currently we are working to formulate the development programs and plans of fire science and technology for the 11th "five-year plan." In the future 5 years, the fire research work will be developed on theory of fire dynamic and fire risk, evaluation on urban area fire risk and capability of fire protection, techniques of new type fire facilities and engineering application, modernization of fire equipment, techniques of assessment and design on fire resistant of construction configuration, human behavior in fire, establishment and improvement of fire database, economics of fire protection and performance-based fire safety engineering.

In the development of fire science and technology, while continuing to introduce advanced technologies from foreign countries, we should attach greater importance to the original creation and system-integrated innovation ability, put stress on the prevention of fires to mitigate fire casualties, and strive to make breakthroughs in the key technologies of fire prevention. We shall put equal emphasis on fundamental research, application technology development and science popularization, accelerate the conversion of research accomplishments to practical productive force and fire control abilities, improve citizen's scientific qualifications and fire safety awareness, and reinforce our efforts to cultivate and forge a highly qualified research team with independent innovation capabilities.

\section{CONCLUDING REMARKS}

Science and technology is the common wealth of human being. Under the background of globalization, it is more important to enhance the close and broad international cooperation and exchange on fire safety science and technology to deal with the challenge of fire. The holding of the 8th IAFSS symposium is such a successful example. There is no boundary between countries on science and technology. We will actively advance the cooperation and exchanges on fire safety science and technology between 
China and other countries to promote the development and advancement of fire science and technology to get a safer and better environment in China and the rest of the world.

\section{REFERENCES}

[1] Guo, T., "Fire Situation in 2004 and Fire Tendency as well as Countermeasures in the Future," Fire Science and Technology 24(3): 263-266 (2005).

[2] Fire Department of the Ministry of Public Security, China Fire Yearbook 2004, China Personnel Press, 2005.

[3] National Bureau of Statistics of China, China Statistical Abstract 2005, China Statistics Press, 2005.

[4] National Bureau of Statistics of China, China Statistical Yearbook 2004, China Statistics Press, 2004.

[5] Wang, H. and Fan, W., "Progress and Problems of Fire Protection in China," Fire Safety Journal 28: 191-205 (1997).

[6] Wu, Q., "Severity of Fire Situation and Impendency of Establishing Knowledge System of Fire Safety Science and Fire Protection Engineering," Fire Science and Technology 24(2): 145-152 (2005).

[7] Wang, M., "Comparison of Fire among China and England, U.S.A, Japan, etc," Fire Technique and Products Information (12): 63-65 (2003).

[8] World Fire Statistics, Information Bulletin of the World Fire Statistics Centre, International Association for the Study of Insurance Economics, Oct. 20, 2004.

[9] "High Sensitivity Smoke Detecting and Alarming System by Aspiration," Shenyang Fire Research Institute of the Ministry of Public Security Research Report 998606, 2003.

[10] "Compound Detecting and Alarming System by Detecting both Smoke and Temperature," Shenyang Fire Research Institute of the Ministry of Public Security Research Report 968621, 1999.

[11] "Double-Wave-Band Infrared Blaze Detecting and Alarming System," Shenyang Fire Research Institute of the Ministry of Public Security Research Report 968619, 2000.

[12] "Line type Combustible Gas Detecting and Alarming System," Shenyang Fire Research Institute of the Ministry of Public Security Research Report S95B101, 1998.

[13] Li, J., Yin, F., Dong, W., and Mei, Z., "Research on Evaluation of Fire Detection Algorithms," Fire Safety Science 14(3): 144-149 (2005).

[14] Hua, J., Liao, G., and Fan, W., "Study on Monitoring and Predicting Method for Boilover Fires Part II—Experimental Analysis," Fire Safety Science 5 (1): 28-34 (1996).

[15] Song, B., Jin, W., and Liu, J., "Experimental Analysis on Water Droplet Kinetic Performance of ESFR Automatic Sprinkler Head," Fire Science and Technology 22(3): 213-216 (2003). 
[16] Jing, J. and Xie, D., "Optimizing Heptafluoride Propane Fire Extinguishing System," Fire Science and Technology 22(1): 40-42 (2003).

[17] Fu, Z. and Yang, R., "Research on Improving Performance of Solid Particulate Aerosol Fire Suppressants Agent," Fire safety science 9(3): 35-41 (2000).

[18] "Computer Processing System for Holographic Image of Droplet Field," Shanghai Fire Research Institute of the Ministry of Public Security Research Report, 1993.

[19] "Study on Fire Extinguishing Efficiency of Flow Field Characteristics of Fine Water Mist," Shanghai Fire Research Institute of the Ministry of Public Security Research Report, 1999.

[20] "Study on Fine Water Mist Fire Systems," Tianjin Fire Research Institute of the Ministry of Public Security Research Report, 2001.

[21] Ye, H., Hu, Y., and Sun, Y., "Development of SD series Intensifying Extinguishing Liquid," Fire Science and Technology 3: 7-10 (1993).

[22] "Application Technology on High Efficiency Water-based Extinguishing Agent," Tianjin Fire Research Institute of the Ministry of Public Security Research Report, 1996.

[23] "Intelligent Fire Detecting and Alarming System in High-rise Building," Shenyang Fire Research Institute of the Ministry of Public Security Research Report, 1995.

[24] "Research on Quick-response Automatic Sprinkler System in High-rise Building," Tianjin Fire Research Institute of the Ministry of Public Security Research Report, 1995.

[25] "Research on Automatic Circulation Close-Open Sprinkler System in High-rise Building," Tianjin Fire Research Institute of the Ministry of Public Security Research Report, 1995.

[26] "Remote Control Fire Extinguishing System of Big Foam (Water) Gun," Shanghai Fire Research Institute of the Ministry of Public Security Research Report 93HJ (405), 1995.

[27] "Series of Middle and Low Pressure Fire Pumps," Shanghai Fire Research Institute of the Ministry of Public Security Research Report H94B107, 1997.

[28] "Research on Basic Parameters and Tester for Fire Shield of Fire Fighter," Shanghai Fire Research Institute of the Ministry of Public Security Research Report H94B107, 1997.

[29] "Research on Industrial Test and Application of Automatic Big Fire Gun," Shanghai Fire Research Institute of the Ministry of Public Security Research Report, 2003.

[30] "Study on Information Integrated and Processing Technology of Fire Detective Robot," Shanghai Fire Research Institute of the Ministry of Public Security Research Report 012512139, 2004. 
[31] "Fire Fighting Command by Satellite Communication System," Shanghai Fire Research Institute of the Ministry of Public Security Research Report 2087A02, 2003.

[32] "Ranking Method on Burning Behavior of Building Materials," Sichuan Fire Research Institute of the Ministry of Public Security Research Report, 1994.

[33] Han, L., "Theoretical Calculation for Fire Resistant Time of Concrete Beamcolumn Filled with Steel Tubular and Its Engineering Practice," Fire Science and Technology 1: 14-16 (2000).

[34] Qu, L., "Effect of Fire Load and Ventilation Factors on Fire Resistant Stability of Reinforced Concrete with Axial-Stress," Fire Science and Technology 6: 4-6 (2001).

[35] Li, Y., Chen, J., and Ji, G., "Characteristics of Building Material's Response to Fire and Ranking System," Fire Science and Technology, 5: 17-19 (2001).

[36] Dong, Y., "Evolution, Global Safety and Spread of Fires," Journal of Safety and Environment 1(2): 1-6 (2001).

[37] Li, Z., "Development of Fire Protection Technology for High-rise Building in China," Fire Science and Technology 1: 18-20 (1999).

[38] Li, B., "Experimental Method of Biologic Identification for Fire Smoke Toxicity," Sichuan Fire Research Institute of the Ministry of Public Security Research Report, 1996.

[39] Li, B., "Principles of Test Methodology for Ranking Toxicity by Fire Production of Materials," Fire Science and Technology 22(6): 445-448 (2003).

[40] Li, Y., Chen, J., Chen, X., Ma, D., and Dong, Y., "Experimental Investigation on Toxicity of Building Materials in Fire," Fire Safety Science 1(1): 37-44 (1992).

[41] Liu, J., Lan, B., Zhang, W., Mei, X., Zhang, Q., and Wan, S., "Experimental Investigation on Smoke Components in the Underground Shopping Centre Fire," Fire Science and Technology 1: 10-12 (2001).

[42] Li, Z. and Wang, W., "Techniques on Air Supplying by Positive Pressurizing for Stair Well in High-rise Building," Sichuan Fire Research Institute of the Ministry of Public Security Research Report, 1995.

[43] Qin, W., "Study on Thin Expanded Fire Prevention Paint for Steel Structure", Fire Science and Technology 3: 35-36 (1998).

[44] "Research on Test Methodology for Ranking Toxicity of Materials," Sichuan Fire Research Institute of the Ministry of Public Security Research Report, 1996.

[45] Zhang, Z., Qin, W. Lan, B., and Li, F., "Research on Characteristic and Mechanism of Nanometer Size LDHs for PS," Proceedings of Scientific Development Concept and Public Fire Safety of 2005 Annual Academy Symposium by China Association for Science and Technology, China Fire Protection Association, 2005, pp. 98-102. 
[46] "SCB Super-thin Expanded Fireproof Coating for Protection of the Steel Constructions," Sichuan Fire Research Institute of the Ministry of Public Security Research Report, 1997.

[47] "SWB \& SWH of Fireproof Coatings for Exterior Steel Structures," Sichuan Fire Research Institute of the Ministry of Public Security Research Report, 1994.

[48] "GF Organic and SF Inorganic Fireproof Filling," Sichuan Fire Research Institute of the Ministry of Public Security Research Report, 1998.

[49] Lin, S., "Principle of Combustion and Burning Patterns," Fire Technique and Products Information 12: 70-74 (2004).

[50] Li, J. and Huang, Z., "Experimental Investigation on Flashover Chemical Characteristics of Wood Materials," Fire Science and Technology (1): 5-9, 33 (1994).

[51] Fan, W.C. and Wang, J., "Predictions of Unsteady Burning of a Fuel Bed. In: Geoffrey Cox and Brian Langford eds," Fire Safety Science - Proceedings of the Third International Symposium, Essex: Elsevier Science Publishers LTD, 1991, pp. 325-334.

[52] Zhang, H., Cai, Z., Fan, W., Zhang, J. and Shields, T.J., "Experimental Investigation on Behavior of Plywood Lining in Room Fires," Fire Safety Science 8(2): 21-28 (1999).

[53] Ye, H., Fu, X., Hu, Y., Fu, Y., Zhao, D., Xue, G., Li, J., Mi, Y., Feng, S., and Huang, Q., "Fire Hazard Assessment of Ethanol Gasoline for Vehicle and Countermeasures," Fire Science and Technology 24(1): 31-35 (2005).

[54] Chen, X., Deng, Z., and Yang, L., "Design and Introduction to Experimental Apparatus for Studying Early Stage of Fire," Fire Safety Science 9(2): 55-60 (2000).

[55] Dong, X. and Yang, Y., "Mathematical Modeling of the Self-Heating Behaviour of Dusts around a Power Cable," In: Michel Curtat eds. Fire Safety Science Proceedings of the Sixth International Symposium, International Association for Safety Science, 2000, pp. 603-610.

[56] Gong,Y., Gu, W., and Tong, J., "Ignition Capability of Friction Sparks and Hot Surface for Fire Risk," Fire Safety Science 8(1): 1-14 (1999).

[57] Shi, H., Fang, M., Wang, S., Yu, C., Luo, Z., and Cen, K., "Research on Pyrolysis Characteristics and Kinetics of typical Combustible Textile," Fire Science and Technology 22(6): 436-440 (2003).

[58] Liu, N., Wang, B., and Fan, W., "Kinetic Compensation Effect in the Thermal Decomposition of Biomass in Air Atmosphere," In: David D. Evans eds. Fire Safety Science - Proceedings of the Seventh International Symposium, International Association for Safety Science, 2003, pp. 581-592.

[59] Chen, Y., Jing, J., Tian, L., Liu, Z., and Lu, Z., "Investigation on Fire Hazard Ranking System of Thermal Unstable Material," Fire Science and Technology 24(1): 5-8 (2005). 
[60] Jiang, H., Fu, Z., Liu, Y., and Liu, H., "Investigation on Thermal Explosion Hazard of Hydrogen Peroxide," Fire Science and Technology 23(2): 121-124 (2004).

[61] Yan, J., Wang, X., and Gao, Y., "Numerical Simulation of Temperature and Velocity in Three-Dimensional Single Room Fire," Fire Science and Technology 22(4): 267-270 (2003).

[62] "Research on Hydraulic Modeling for Fire Smoke Flow," Tianjin Fire Research Institute of the Ministry of Public Security Research Report, 1997.

[63] "Research on Performance-based Fire Protection Design Method for Atrium Building and Its Application," State Key Lab of Fire Science of University of Science and Technology of China Research Report 2001BA803B02, 2004.

[64] "Research on Characteristics of Fire in Underground Supermarket," Tianjin Fire Research Institute of the Ministry of Public Security Research Report, 2001.

[65] "Experimental Investigation on Smoke Flow Characteristics in Underground Shopping Center Fire," Sichuan Fire Research Institute of the Ministry of Public Security Research Report, 2000.

[66] Huo, R., Li, Y., Yu, M., You, F., and Zhou, Y., "Preliminary Investigation on Mechanical Exhaust in Large Space Building," Fire Science and Technology (4): 3-5 (2001).

[67] "Study on Guide for Performance-based Fire Safety Design in Building," Tianjin Fire Research Institute of the Ministry of Public Security Research Report 2001BA803B02, 2004.

[68] "Study on Evaluating Technology of Performance-base Fire Design in High-rise Buildings," Sichuan Fire Research Institute of the Ministry of Public Security Research Report 2001BA803B02, 2004.

[69] "Application Research on Performance-base Fire Protection Design for Large Space with Crowd in Mass," Fire Protection Institute of China Academy of Building Research Report 2001BA803B02, 2004.

[70] Li, Y., Xiao, Z., Zhang, X., Tang, H., Liu, W., Tong, Y., Li, L., and Sun, X., "Computer Model for Fire Safety Evacuation," Proceedings of Scientific Development Concept and Public Fire Safety of 2005 Annual Academy Symposium by China Association for Science and Technology, China Fire Protection Association, 2005, pp. 76-80.

[71] Zhou, Y., Fan, W., and Chen, L., "Full-scale Experiments on Atrium Fire," Fire Safety Science 2(2): 61-64 (1993).

[72] Wang, G., Huo, R., Yi, L., and Zhou, Y.. "Discussions on Application of Hot Smoke Test for Evaluating Smoke Management Systems of Building," Fire Science and Technology 24(1): 25-27 (2005).

[73] Fu, Z. and Fan, W.C., "A Zone Type Model for a Building Fire and Its Sensitivity Analysis," Fire and Material 20: 215-224 (1996). 
[74] "Study on Prevention and Control Technology of Urban Fires and Severe Chemical Accidents," Shanghai Fire Research Institute of the Ministry of Public Security Research Report 2001BA803B02, 2004.

[75] "Study on Guide for Urban Fire Layout," Tianjin Fire Research Institute of the Ministry of Public Security Research Report 2001BA803B02, 2004.

[76] "Studies on the Technology of Evaluating Regional Fire Risks in Urban Area," The Chinese People's Armed Policy Forces Academy Research Report 2001BA803B02, 2004.

[77] "Study on Optimizing Forces for Fire Fighting and Rescue in City," Shanghai Fire Research Institute of the Ministry of Public Security Research Report 2001BA803B02, 2004.

[78] Wu, J. and Hu, C., "Study on the Method of Optimizing Collocate-Fire Fighting Based on Regional Fire Risks," Proceedings of Scientific Development Concept and Public Fire Safety of 2005 Annual Academy Symposium by China Association for Science and Technology, China Fire Protection Association, 2005, pp. 33-36.

[79] "Ranking Grade-Class Means of City Fire and Other Disasters," Shenyang Fire Research Institute of the Ministry of Public Security Research Report 2001BA803B02, 2004.

[80] "Fire Dynamics and Fundamentals of Fire Protection," University of Science and Technology of China, Tsinghua University, Zhejiang University, Hong Kong Polytechnic University, Sichuan Fire Research Institute of the Ministry of Public Security, Shenyang Fire Research Institute of the Ministry of Public Security, Shanghai Fire Research Institute of the Ministry of Public Security, and Chinese Academy of Forestry Project Contract 2001CB409600, 2002.

[81] "The Evolvement of Fire Dynamics and The Basic Of Prevention and Cure," University of Science and Technology of China, Tsinghua University, Zhejiang University, Hong Kong Polytechnic University, Sichuan Fire Research Institute of the Ministry of Public Security, Shenyang Fire Research Institute of the Ministry of Public Security, Shanghai Fire Research Institute of the Ministry of Public Security, and Chinese Academy of Forestry Project Middle Summary Report 2001CB409600, 2004. 